\title{
A review of cardiovascular disease induced by radiation
}

Review article

\author{
Isa Sincer, Aslı Kurtar Mansiroglu
}

Department of Cardiology, Abant Izzet Baysal University, Medical School, Bolu, Turkey

\section{ABSTRACT}

Cardiovascular diseases are still in the 1st place in the world among cause of deaths. Data accumulates about publications investigating the effect of radiation on cardiovascular disease. Ionized radiation is used for diagnosis and treatment of many disease, recently. As for invasive cardiology; coronary artery disease, cardiac valve diseases, electrophysiological studies require radiation assistance. It is very important for invasive cardiologists to know the cardiovascular adverse effects of radiation and radiation protection methods.

Keywords: Cardiovascular disease; radiation; invasive cardiology.

Copyright $(02018$ experimentalbiomedicalresearch.com

Corresponding Author: Isa Sincer, M.D.

Abant Izzet Baysal University, Medical School, Department of Cardiology, Bolu, Turkey.

E-mail: isasincer@yahoo.com

Received 2017-12-18 Accepted 2018-01-21

\section{Introduction}

Cardiovascular (CV) diseases caused about 17, 7 million deaths worldwide in 2015. I doubles the death rate of cancer, which caused 8,8 million of death in the same year [1]. Two fold increase in cardiovascular deaths compared to cancer related deaths suggest the importance of cardiovascular diseases. Effects of radiation on cardiovascular system has attracted great attention of the researchers nowadays. Most of these studies were conducted in cancer patients received radiation therapy. We will describe some of these studies in present review.

Radiation has adverse effects on heart and vasculature even at conventional doses in long term. Risk of cardiovascular disease increased by the increasing doses of radiation. Elevated dose of radiation cause functional and structural abnormalities in heart, especially, at myocardium, pericardium, heart valves and coronary arteries [2].

\section{Pathophysiology of CV damage induced by radiation}

Fibrinous exudative formation and fibrosis are initial pathological mechanism in radiation driven heart disease, and repeated ischemic attacks cause deterioration in microvascularity of pericardium by endothelial damage. This damage eventually cause an increase in fibroblast and collagen in pericardial tissue [3]. Damage of radiation in endocardium includes decreased capillary circulation due to ultra-structural changes. Transforming growth factor-beta up-regulated in epicardial vasculature, which triggers prothrombic state. In addition, activated nuclear 
factor-kB in endothelium, stimulates continuous inflammation [4-7]. This prothrombotic environment give rise to secondary vascular obliteration after activation of macrophages and monocytes inflammation. In a rat study, radiation caused development of unstable plaques, caused by macrophage infiltration and hemorrhage within plaque after radiation exposure [8]. Endothelial dysfunction in coronary vessels developed 6 months after radiation exposure in another rat study [9]. Although patients received high dose radiation remain asymptomatic initially, coronary artery disease develop after 5 to 20 years later [2].

Myocardial changes induced by radiation includes, myocardial fibrosis secondary to degeneration of myocardial capillary endothelium [10].

Initially, radiation cause valvular regurgitation by retraction of the heart valves, however, stenosis develop after calcification and fibrosis and thickening of the valves. Radiation associated damage is $79 \%$ more common in left sided valves according to autopsy series [11-13]. Beside deterioration in myocardium, endocardium and heart valves, conduction system may also be affected by radiation [14]. Radiation stimulates sympathetic nervous system by enhancing beta adrenergic receptors. Myocardial injury is increased by autonomic dysfunction [15]. Increased fibrosis driven by radiation may damage conduction system and sinoatrial node, and eventually cause complete heart block [16].

\section{Clinical findings in radiation induced $C V$ diseases}

Adverse effects of radiation is observed in pericardium, coronary vasculature, heart valves, conduction pathways, causing together, cardiomyopathy and autonomic dysfunction $[17,18]$. About $18 \%$ of subjects exposed to radiation dose higher than 3,7 gray developed cardiomyopathy after 20 years [19].

\section{Radiation studies in invasive cardiology}

In MATRIX study, subjects randomize into either radial or femoral access groups. In RAD MATRIX subgroup study, researchers observed 777 interventions in 767 subjects performed by 18 cardiologists [20]. Dosimeters located on thorax, head and wrist measured the radiation dose of exposed by cardiologists and found that thoracal radiation exposure was higher than that of the measured by wrist and cranial dosimeters [20]. Radiation exposures of patients and cardiologists (even specialized radial access operators) were higher in radial access compared to femoral access in the mentioned study [20]. Difference between radial and femoral access groups may be more prominent in complex interventions [20].

Another study observed effects of radiation on DNA damage and beneficial effects of lead apron under knee level. 15 cardiovascular surgeons who perform open surgery and or endovascular aortic repair (EVAR), enrolled to the study. DNA damage was measured $\gamma$ H2AX and pATM in serum samples obtained before the procedure, right after procedure and 24 hours later [21]. Despite pre procedure and post procedure $\gamma$-H2AX and pATM were similar in surgeons done open surgery, both $\gamma$ $\mathrm{H} 2 \mathrm{AX}$ and pATM elevated after procedure compared to pre procedure period in surgeons done complex EVAR (branched or fenestrated EVAR) and only pATM was increased in post procedure compared to pre procedure period in surgeons done infrarenal EVAR. Neither $\gamma$ H2AX nor pATM were elevated in post 
procedure period in surgeons used lead apron under knee level. When the blood from the operators is exposed to the same dose of radiation in-vitro, it has been noted that the DNA damage that occurs is variable individually.

This study showed that acute DNA damage occurs when exposed to radiation. DNA damage was not observed when lead apron at knee level was used. This indicates the importance of scattered radiation received from the lower extremity. In addition, biomarkers above can be used to determine the sensitivity of physicians to radiation damage. Thus, vulnerable persons can be given less radiation $[21,22]$.

In another study, 31 interventional physicians with brain or neck tumor were evaluated. The most common tumor was glioblastoma multiforme $(55 \%)$. In 26 of 31 cases, there were side of tumor data, and in 22 of these 26 cases, the tumors were left sided, one in the middle, and three were right sided. Since, brain tumors are seen equally on both sides, the more left side of the brain is exposed to radiation, so, these tumors may be due to radiation because brain is one of the least protected regions of radiation of interventional cardiologists [23].

\section{Conclusion}

People are receiving more or less radiation from nature or artificially in some way. Ionized radiation is being used in both diagnosis and treatment; primarily as radiotherapy. Ionized radiation is specifically used in invasive cardiology for diagnosis and treatment of coronary artery disease, heart valve disease, and for electrophysiological studies. In most cases, ionizing radiation in invasive cardiology is widely used in coronary artery, valve diseases and electrophysiological procedures. interventional cardiologists expose to excessive and sometimes unnecessary radiation doses in procedures involving heart valves. Using lead aprons, lead glasses and proper lead protectors is necessary. Routine check-up including hemogram, thyroid sonography and eye examination in every 6 months is advised.

\section{Compliance with ethical statements \\ Conflicts of Interest: None.}

\section{References}

[1]WHO. Cardiovascular Diseases (CVDs). WHO; 2017. http://www.who.int/mediacentre/factsheets /fs317/en/

[2]Darby SC, Ewertz M, McGale P, Bennet AM, Blom-Goldman U, Brønnum D, et al. Risk of ischemic heart disease in women after radiotherapy for breast cancer. N Engl J Med. 2013;368(11):987-98.

[3]Fajardo LF. The unique physiology of endothelial cells and its implications in radiobiology. Front Radiat Ther Oncol. 1989;23:96-112.

[4]Greenwood RD, Rosenthal A, Cassady R, Jaffe N, Nadas AS. Constrictive pericarditis in childhood due to mediastinal irradiation. Circulation. 1974;50(5):1033-39.

[5]Schultz-Hector S, Balz K. Radiationinduced loss of endothelial alkaline phosphatase activity and development of myocardial degeneration. An ultrastructural study. Lab Invest. 1994;71(2):252-60.

[6]Krüse JJ, Bart CI, Visser A, Wondergem J. Changes in transforming growth factor-beta (TGF-beta 1), procollagen types I and II mRNA in the rat heart after irradiation. Int J Radiat Biol. 1999;75(11):1429-36. 
[7]Halle M, Gabrielsen A, Paulsson-Berne G, Gahm C, Agardh HE, Farnebo F, et al. Sustained inflammation due to nuclear factor-kappa B activation in irradiated human arteries. J Am Coll Cardiol. 2010;55(12):1227-36.

[8] Stewart FA, Heeneman S, Te Poele J, Kruse J, Russell NS, Gijbels M, et al. Ionizing radiation accelerates the development of atherosclerotic lesions in ApoE-/- mice and predisposes to an inflammatory plaque phenotype prone to hemorrhage. Am J Pathol. 2006;168(2):649-58.

[9] Tungjai M, Whorton EB, Rithidech KN. Persistence of apoptosis and inflammatory responses in the heart and bone marrow of mice following whole-body exposure to ${ }^{28}$ Silicon $\left({ }^{28} \mathrm{Si}\right)$ ions. Radiat Environ Biophys. 2013;52(3):339-50.

[10]Liu LK, Ouyang W, Zhao X, Su ShF, Yang Y, Ding WJ, et al. Pathogenesis and Prevention of Radiation-induced Myocardial Fibrosis. Asian Pac J Cancer Prev. 2017;18(3):583-87.

[11]Basavaraju SR, Easterly CE. Pathophysiological effects of radiation on atherosclerosis development and progression, and the incidence of cardiovascular complications. Med Phys. 2002;29(10):2391-403.

[12]Carlson RG, Mayfield WR, Normann S, Alexander JA. Radiation-associated valvular disease. Chest. 1991;99(3):538-45.

[13] Wethal T, Lund MB, Edvardsen T, Fosså SD, Pripp AH, Holte H, Kjekshus J, Fosså A. Valvular dysfunction and left ventricular changes in Hodgkin's lymphoma survivors. A longitudinal study. $\mathrm{Br} \mathrm{J}$ Cancer. 200918;101(4):575-81.

[14] Yusuf SW, Venkatesulu BP, Mahadevan LS, Krishnan S. Radiation-Induced
Cardiovascular Disease: A Clinical Perspective. Front Cardiovasc Med. 2017; 26;4:66.

[15] Schultz-Hector S, Böhm M, Blöchel A, Dominiak P, Erdmann E, MüllerSchauenburg W, Weber A. Radiationinduced heart disease: morphology, changes in catecholamine synthesis and content, beta-adrenoceptor density, and hemodynamic function in an experimental model. Radiat Res. 1992;129(3):281-89.

[16] Slama MS, Le Guludec D, Sebag C, Leenhardt AR, Davy JM, Pellerin DE, Drieu LH, Victor J, Brechenmacher C, Motté G. Complete atrioventricular block following mediastinal irradiation: a report of six cases. Pacing Clin Electrophysiol. $1991 ; 14(7): 1112-28$.

[17]Nielsen KM, Offersen BV, Nielsen HM, Vaage-Nilsen M, Yusuf SW. Short and long term radiation induced cardiovascular disease in patients with cancer. Clin Cardiol. 2017;40(4):255-61.

[18] Yusuf SW, Sami S, Daher IN. Radiationinduced heart disease: a clinical update. Cardiol Res Pract. 2011;27;2011:317659.

[19] Guldner L, Haddy N, Pein F, Diallo I, Shamsaldin A, Dahan M, et al. Radiation dose and long term risk of cardiac pathology following radiotherapy and anthracyclin for a childhood cancer. Radiother Oncol. 2006;81(1):47-56.

[20] Sciahbasi A, Frigoli E, Sarandrea A, Rothenbühler M, Calabrò $\mathrm{P}$, Lupi A, et al. Radiation Exposure and Vascular Access in Acute Coronary Syndromes: The RAD-Matrix Trial. J Am Coll Cardiol. 2017;69(20):2530-37.

[21]El-Sayed T, Patel AS, Cho JS, Kelly JA, Ludwinski FE, Saha $P$, et al. Radiationinduced DNA damage in operators 
performing endovascular aortic repair. Circulation. 2017;136(25):2406-16.

[22]Borghini A, Vecoli C, Mercuri A, Carpeggiani C, Piccaluga E, Guagliumi G, et al. Low-Dose Exposure to Ionizing Radiation Deregulates the Brain-Specific MicroRNA-134 in Interventional Cardiologists. Circulation. 2017; 136(25):2516-18.

[23] Roguin A, Goldstein J, Bar O, Goldstein JA. Brain and neck tumors among physicians performing interventional procedures. Am J Cardiol. 2013;111(9):1368-72. 